\title{
Influence de la salinité de l'eau de boisson sur les teneurs plasmatiques en minéraux d'ovins nourris avec de la paille
}

\author{
T Meziane 1, B Safsaf 1, B Lachili 2, F Benlatreche ${ }^{3}$ \\ IInst Sci Vét, Université de Batna (05000) ; 2Inst Sci Méd, Université de Batna (05000); \\ 3/NESSM Constantine (25000), Algérie
}

Le sud des hauts plateaux sétifiens est caractérisé par l'existence de chotts salés autour desquels viennent paître les ovins. II n'existe pas d'informations sur l'influence de la composition minérale de l'eau de boisson et des aliments sur le statut minéral des animaux de la région.

Quatre élevages extensifs d'ovins de la région ont été choisis selon le niveau de la salinité de l'eau : eau sulfurée (HS), eau sulfatée (S) et eau salée (Salé) situés autour du chott, et eau douce $(T)$ au nord de la région. Dans chaque ferme, des prélèvements sanguins ont été effectués sur dix brebis âgées de 2-3 ans, gestantes de 2 à 3 mois, de race Ouled djellal et nourris avec de la paille. Le sang est prélevé sur de l'heparinate de lithium. Les taux plasmatiques de $\mathrm{Ca}, \mathrm{Mg}, \mathrm{Na}, \mathrm{K}, \mathrm{Cu}, \mathrm{Zn}, \mathrm{Mn}$ sont déterminés par absorption atomique, ceux de $\mathrm{Fe}$ et de $\mathrm{P}$ par colorimétrie.

Dans la plupart des cas, il existe des différences significatives entre les teneurs en minéraux des animaux testés $(P<0.05)$. Malgré ces différences, les taux plasmatiques de $\mathrm{Mg}$, $\mathrm{P}, \mathrm{Na}, \mathrm{K}, \mathrm{Fe}$ restent dans les normes (Underwood, 1981, The mineral nutrition of livestock ; Grace, New Zealand J Agric Res, $1990,33,635)$.

La calcémie des animaux buvant l'eau sulfatée reste normale alors que les animaux des autres lots présentent une hypocalcémie. Tous les animaux sont carencés en $\mathrm{Mn}, \mathrm{Cu}, \mathrm{Zn}$ sauf la ferme (S) pour le Cu.

Les eaux bues par les animaux dans cette région semblent ne pas avoir une influence néfaste sur le métabolisme minéral.

Au contraire, l'absorption de l'eau sulfatée (S) semble compenser l'hypocalcémie et l'hypocuprémie observées dans les fermes HS ; T ; Salé.

Les variations des effets de l'eau de boisson de cette région à long terme et à différents stades physiologiques méritent d'être étudiés.

\begin{tabular}{|c|c|c|c|c|c|c|c|c|c|c|}
\hline & & $\begin{array}{c}\mathrm{Ca} \\
(\mathrm{mg} / \mathrm{l})\end{array}$ & $\underset{(\mathrm{mg} / /)}{\mathrm{P}}$ & $\begin{array}{c}\mathrm{Mg} \\
(\mathrm{mg} / \mathrm{l})\end{array}$ & $\begin{array}{l}\mathrm{Na} \\
(\mathrm{g} / \mathrm{l})\end{array}$ & $\begin{array}{c}\mathrm{K} \\
(\mathrm{mg} / \mathrm{l})\end{array}$ & $\begin{array}{c}\mathrm{Fe} \\
(\mathrm{mg} / \mathrm{l})\end{array}$ & $\underset{(\mathrm{mg} / \mathrm{ll})}{\mathrm{Cu}}$ & $\underset{(\mathrm{mg} / \mathrm{l})}{\mathrm{Zn}}$ & $\begin{array}{c}\mathrm{Mn} \\
(\mu \mathrm{g} / \mathrm{l})\end{array}$ \\
\hline Témoin & $(\mathrm{T})$ & $80,1^{\mathrm{bd}}$ & 60,2 & $18,1^{\mathrm{a}}$ & $3,54^{a}$ & $202^{a}$ & $1,08^{a}$ & $0,41^{a}$ & $0,62^{a}$ & $2,86^{a}$ \\
\hline $\mathrm{HS}$ & & $85,4^{b}$ & $58,2^{\mathrm{a}}$ & $23,7^{\circ}$ & $3,85^{\circ}$ & 219 & $1,43^{b}$ & $0,41 \mathrm{a}$ & $0,69^{\circ}$ & $3,37 a$ \\
\hline $\mathrm{S}$ & & $94,8^{a}$ & $66,9^{\circ}$ & $25,1^{b}$ & $4,31^{c}$ & $229 \mathrm{~b}$ & $1,67^{c}$ & $0,89 \mathrm{~b}$ & $0,38^{b}$ & $4,79^{b}$ \\
\hline Salé & & $77,3^{c d}$ & $71,6^{b}$ & $25,5^{b}$ & 4,04 & 214 & $1,33 \mathrm{ab}$ & $0,65^{c}$ & $0,62^{\mathrm{a}}$ & $1,87^{\circ}$ \\
\hline \multirow[t]{2}{*}{ Normes } & $(\min )$ & 90 & 37 & 18 & 3 & 147 & 1,02 & 0,80 & 0,8 & 20 \\
\hline & axx) & 116 & 81 & 27 & 3,3 & 200 & 3,04 & 1,20 & 1,8 & \\
\hline
\end{tabular}

